\title{
Tryptophan Enhancement/Depletion and Reactions to Failure on a Cooperative Computer Game
}

Janet Wingrove, M.Phil., Alyson J. Bond, Ph.D., and Anthony J. Cleare, M.B.B.S., M.R.C.Psych., Ph.D.

Twenty-eight high trait hostility male volunteers played a "cooperative" computer game 4.5 hours after an amino acid drink enhanced with, or depleted of, tryptophan. Each trial involved steering a tank through minefields following directions from an unknown "partner." Failure was experienced when the tank hit a mine or when time ran out. Subjects' moods, verbal aggression, attributions of blame, vocal acoustics, and blood pressure were assessed.

Differences between tryptophan groups were not significant for primary measures of anger and verbal aggression.

However, depleted subjects reported greater increases in feelings of restlessness and incompetence, were less successful in avoiding mines and showed greater increases in blood pressure during the game. Subjects in both groups sent more negative ratings when they lost the game by virtue of hitting a mine rather than losing by running out of time. However, ratings of the depleted group were less influenced by the reason for losing the game. Also, vocal acoustics showed a group $\times$ reason-for-losing interaction in the high-frequency band. Tryptophan-depleted subjects with high scores on Behavioral-Activation-System-Drive were most likely to send negative ratings and those scoring high on Buss-Durkee Hostility Inventory Assault and Guilt to report increased anger after the game.

[Neuropsychopharmacology 21:755-764, 1999]

(C) 1999 American College of Neuropsychopharmacology. Published by Elsevier Science Inc.
KEY WORDS: Serotonin; Tryptophan; Aggression; Hostility; Blood pressure

Evidence has been accumulating that the serotonergic system may be involved in the processes underlying at least some types of aggressive behavior. Most of this research in humans has been correlational. It has sought to demonstrate relationships between a history of ag-

From the Section of Clinical Psychopharmacology (JW, AJB), Institute of Psychiatry, King's College, London, and Department of Psychological Medicine (AJC), Institute of Psychiatry, King's College, London, UK.

Address correspondence to: J. Wingrove, Kings College, Institute of Psychiatry, Section of Clinical Psychopharmacology, London SE5 8AF, UK.

Received January 25, 1999; revised June 9, 1999; accepted June 17, 1999. gressive behavior or trait measures of hostility on the one hand, and, on the other, various markers of serotonergic function. The latter have included plasma concentration of the 5-HT precursor tryptophan, CSF concentration of its metabolite 5-HIAA, and endocrine responses to serotonergic agents (for review see Verhoeven and Tuinier 1997). Findings from these studies include higher levels of plasma tryptophan in men who had committed violent crimes than non-offender controls (Eriksson and Lidberg 1997); and in men with personality disorders, negative correlations between history of aggression and CSF 5-HIAA (Brown et al. 1979), and between the Assault subscale of the Buss-Durkee Hostility Inventory (BDHI) and the prolactin response to d-fenfluramine (Coccaro et al. 1996). However, in correlational studies, it is difficult to disentangle the possible influence of other variables. For example, individuals who score high on history of aggression often 
also have a history of suicide attempts and affective disorder. Experimental methods are, therefore, an important complementary research strategy.

A small number of experimental studies have used the technique of tryptophan depletion to test the hypothesis that low levels of central serotonin increase the probability of anger and/or aggression. An early study using healthy male volunteers found no effect of tryptophan depletion on hostile mood (Young et al. 1985), or on aggressive behavior in a modified Buss paradigm (Smith et al. 1986). However, the importance of individual differences in susceptibility to the depressogenic effects of tryptophan depletion was becoming apparent (see Benkelfat et al. 1994), and it seemed possible that a similar relationship might be true for aggression. This was tested by Cleare and Bond (1995), who found that depletion (relative to enhancement) increased both subjective anger and objective aggressive behavior on the Competitive Reaction Time (CRT) task in high trait hostility, but not low trait hostility, healthy male volunteers. The importance of trait hostility has been supported by subsequent studies. Finn et al. (1998) found a correlation between decrease in plasma tryptophan following depletion and increase in hostile mood in high, but not low, trait hostility subjects. Moeller et al. (1996) found a depletion-induced increase in aggressive responding, which correlated with baseline aggressive responses, on the Point Subtraction Aggression Paradigm (PSAP). The effect of tryptophan depletion on aggression has also been supported by Pihl et al. (1995), who found higher aggression on the CRT following depletion (relative to enhancement) in healthy male volunteers, although the effect was only significant in the low provocation condition.

In addition, an effect of tryptophan depletion on anger or irritability has been noted in a few studies in which aggression was not the primary focus. For example, increases in irritability following depletion were found in women with bulimia (Weltzin et al. 1995) and in women with late luteal phase dysphoric disorder (Menkes et al. 1994). Danjou et al. (1990) found an increase on self-rated anger after depletion in male healthy volunteers. A negative result was reported by Salomon et al. (1994), who did not find any evidence of increased anger or aggression after depletion in a patient group with diagnoses of Intermittent Explosive Disorder. However, aggressive behavior may be unlikely to occur in a research setting without some triggering situation or event, and self-ratings of mood require a degree of mood awareness that may not exist in all groups.

Despite a number of significant findings, the psychological mechanisms involved in the putative serotoninaggression link are, as yet, largely unexplored. However, a role for impulsivity has been suggested (see e.g. Higley et al. 1996; Baumgarten and Grozdanovic 1995).
Cleare and Bond (1995) found that both high- and lowhostility subjects in the depletion condition were quicker to set the noise levels for their opponents than their enhanced counterparts, a result consistent with an effect of depletion on impulsivity. On the other hand, the effects of tryptophan depletion on mood found in that study, and others, leave open the possibility that mood changes might be the primary effect. Of course, these possibilities are not mutually exclusive. Tryptophan depletion may have a number of effects on psychological function, and several of these may have consequences for the probability of aggressive behavior.

This study has several aims. First, in view of the somewhat mixed findings to date, we aimed to replicate the effect of tryptophan depletion on angry mood in a high trait hostility group found by Cleare and Bond (1995). The study was restricted to high-hostility participants, because previous research suggests that tryptophan depletion may have little, if any, effect on those low on trait hostility. Women were excluded because of the practical constraints imposed by the need to control for menstrual cycle status. A second aim was to test the generality of the effect of tryptophan depletion on aggressive behavior. Depletion-induced increases in aggression have been found using the CRT (Cleare and Bond 1995; Pihl et al. 1995) and the PSAP (Moeller et al. 1996). In both these paradigms, the aggression is presumably elicited primarily by provocation from an opponent. This takes the form of electric shocks or bursts of white noise in the CRT and subtraction of points (and, thus, money) in the PSAP. The subject is given the opportunity to retaliate in kind. However, people also become aggressive in situations in which they have not been directly attacked; for example, when they experience failure or frustration. Therefore, the present study used a cooperative computer game in which the subjects experience failure (Wingrove and Bond 1998). The game was intended to expose all participants to a qualitatively similar experience of failure. However, to increase the credibility of the task, some variation in outcome depended upon how well the participants followed the directions sent by the "partner." This task complements the CRT task used previously by Cleare and Bond (1995) in that it is cooperative rather than competitive and assesses verbal rather than physical aggression. The primary research hypotheses were, therefore, that the depleted participants would show higher scores on self-reported anger at 4.5 hours and subsequently send more negative ratings and messages to their "partners" during the Tanks game. In addition, increased anger in depleted participants might be reflected in greater increases in blood pressure, higher scores on attribution of blame to the partner for failure, and changes in the acoustic properties of voice recordings made while giving feedback during the game. These measures were used in a more exploratory way 
with the aim of developing hypotheses about the psychological mechanisms that might contribute to the effect of tryptophan depletion on aggressive behavior. Given the apparent importance of individual differences in response to tryptophan depletion, a further aim was to explore these further by using range of trait measures, including anxiety, depression, impulsivity, and behavioral activation and inhibition.

\section{METHODS}

\section{Subjects}

Healthy male volunteers aged 18 to 44 years were recruited from a volunteer pool and were paid $£ 55$ for participating. All potential volunteers were asked to complete the Buss Durkee Hostility Inventory (BDHI, Buss and Durkee 1957), and only those with scores on the Motor Aggression subscale of 23 or above were included in the study. None of the volunteers was receiving concurrent medication. Volunteers were screened for any current psychiatric disorder by one of the authors (AJC). The local ethics committee approved the study, and all subjects gave written informed consent.

\section{Design}

In a double-blind independent groups design, 28 subjects were randomly assigned to receive either a tryptophan-enhanced $(\mathrm{T}+)$ or tryptophan-depleted (T-) amino acid drink. Plasma tryptophan was not lowered at 4.5 hours in one subject in the depleted group whose data was, therefore, omitted from all further analyses.

\section{Tryptophan Manipulation}

The depleted drink consisted of a 100-g mix of 15 amino acids excluding tryptophan, and the enhanced drink consisted of the same 100-g mix with the addition of $10.3 \mathrm{~g}$ of tryptophan. Drink composition was as described by Young et al. (1985).

\section{Procedure}

Subjects were asked to arrive at 9 A.M. after an overnight fast and remaining alcohol free for at least 24 hours. They were asked about any illicit drug use, but this was not confirmed by urine screen. Trait questionnaires and baseline mood self-ratings were completed, and a blood sample was taken before the amino acid drink was given. Despite its unpleasant taste, all the subjects were able to consume the drink, which they were encouraged to do as quickly as possible. They then rested quietly. Drinking water was freely available. Testing commenced $41 / 2$ hours after the drink at approximately 2 P.M., when a second blood sample was taken. Mood ratings were completed before and after the Tanks game. An attribution questionnaire was completed at the end of the game. Subjects were given a light meal before leaving.

\section{Tanks Game}

The basic version of this task has been described elsewhere (Wingrove and Bond 1998). The game involves using the left and right mouse buttons to steer a tank on the computer screen through fields to its base within a time limit of 70 seconds. The subjects were told that the fields contained mines, which they could not see, but which could be seen by their partner in an adjacent room. This partner would send them directions (right, left, or straight) that would appear at the top of their screen. To make the task credible, the tank would "blow up" if the directions were ignored. In addition, some tanks would "blow up" regardless of the subject's actions. Other tanks would be lost, because time would run out before the base was reached. It was anticipated that those playing the game would be more likely to blame their partners for losing the game as a result of the tank's hitting a mine than the player themselves taking the blame for loss because of running out of time. This was assumed, because the partner's directions were supposed to help the players avoid hitting the mines. However, losing by running out of time might be a more frustrating experience, because the tank would be lost when close to the goal. There were 20 trials; that is, 20 tanks to be returned to base. After each trial, the score so far (i.e., the numbers of tanks won and lost and still to be played) appeared on the screen. After seeing the score, subjects gave feedback to their partner in two ways. First, by speaking into a microphone. They were told that anything they said while the "please speak now" signal was on the screen would be relayed to their partner. The signal remained on the screen for 5 seconds after the player began to speak. Second, after display of the rating scale, the player pressed a number from 1 (excellent) to 6 (absolutely useless). The players were told that the number and corresponding description would appear on their partner's screen. Play then continued after the ready signal.

\section{Trait Variables}

Trait anxiety and depression were assessed using the Spielberger Trait Anxiety Inventory (STAI, Spielberger et al. 1970) and Beck Depression Inventory (BDI, Beck et al. 1961), respectively. The three subscales (motor, cognitive, and nonplanning) of the Barratt Impulsiveness Scale (BIS-11, Patton et al. 1995) were used to assess impulsivity. Hostility and guilt were assessed with the Motor Aggression, Attitudinal Hostility, and Guilt subscales of the BDHI (Buss and Durkee 1957). The four 
BIS/BAS scales developed by Carver and White (1994) were used to assess sensitivity of the behavioral inhibition and activation systems.

\section{Outcome Measures}

Biochemical. Blood samples were taken into heparinized tubes. They were immediately centrifruged at 3000 $g$ for 10 minutes, and the plasma was frozen at $-20^{\circ} \mathrm{C}$ until analysis. Total plasma tryptophan was measured using high-performance liquid chromatography (HPLC).

Affective. Three sets of self-rating visual analog scales (VAS) were used to assess mood: the Mood Rating Scale (MRS, Bond and Lader 1974); the Anger Rating Scale (ARS, Bond and Lader 1986); and the STIMP (to measure impulsive mood, Wingrove and Bond 1997). For analysis, the three factors of the MRS (sedation/alertness, discontentedness, and anxiety), the mean ARS (anger), and the three subscales of the STIMP (restlessness, behavioral impulsivity, and cognitive impulsivity) were used. The MRS item "happy-sad" was used to test the effect of tryptophan depletion on depressed mood.

Psychophysiological. Blood pressure and pulse were recorded continuously throughout the Tanks game using an Ohmeda 2300 Finapres attached to the subject's finger. Each trial was then divided into three periods, rest (before play starts), play (while playing the game), and end (when score is shown and rating sent to partner). The median for each period was calculated for each subject.

Tank Performance. Performance on the game was estimated by allocating two points for a win, one point for trials on which the subject successfully avoided the mines, but then ran out of time, and no points for trials on which the tank hit a mine.

Start Time. This was measured as the time between a "ready" signal appearing on the screen and the subject pressing the mouse button to start the tank moving.

Rating Time. This was the time between the rating scale appearing on the screen and the subject pressing a numbered key.

Behavioral. The behavioral measures were the ratings (1 to 6) and verbal messages sent to the partner after each trial of the Tanks game. The mean ratings over all trials and over losing trials where the tank hit a mine and over losing trials where the time ran out were calculated for each subject. Three independent raters used the following categories to code the spoken messages:

1. apologies (e.g., "Sorry," "I should have gone further right.");
2. blames or criticizes partner or implies failure was partner's fault (e.g., "You steered me straight into that one," "You have to sort out your left and right.");

3. negative, uncooperative, or angry remarks that do not clearly blame either self or partner (e.g., "Damn those mines.");

4. cooperative, encouraging, or positive remarks (e.g., "Better luck next time.");

5. neutral remarks; and

6. silence where the subject does not speak (including sighs, "ums" and "ers")

Where the raters did not agree, the category coded by two of the three was used.

Attribution of Blame. Subjects were given a list of 24 possible reasons for performing poorly on the game and were asked to rate each as not a reason (scoring 1 point), a minor reason ( 2 points), or a major reason (3 points) for their own poor performance. Ten of these were "self-blame" items (e.g., "My reactions were too slow."). Eight attributed blame to the partner, of which four implied that this was the partner's fault ("intentional blame" e.g., "My partner gave wrong directions deliberately."). A further four attributed blame to the partner but without implying that it was intentional ("nonintentional blame" e.g., "My partner was too slow."). Four items ascribed blame to the task (e.g., "The equipment was poor.") and two to chance (e.g., "It was bad luck."). [N.B. This questionnaire has been refined since the earlier version reported in Wingrove and Bond (1998).]

Voice. Fourier analysis was performed on the voice data collected from the verbal messages sent at the end of each trial. For each subject, the fundamental frequency, peak amplitude, and mean amplitude in each of seven frequency bands was calculated for each trial: 80-256, 256-512, 512-1024, 1024-2048, 2048-4096, 4096$5120,5120-8176 \mathrm{~Hz}$.

\section{Data Analysis}

Differences between the groups on variables measured once only (i.e., baseline trait and state measures, performance on the Tanks game, scores on Attribution Questionnaire) were tested using one-way analysis of variance (ANOVA). To look at the effect of tryptophan group and time on mood, it was first established that there were no significant differences at baseline for mean ARS, MRS factors, and STIMP grouped items. Then time $\times$ group ANOVAs were performed on the change scores calculated by subtracting the baseline rating from each of the afternoon ratings (pre- and postTanks game). Variables measured on each trial of the Tanks game (i.e., ratings, rating time, start time, BP, and 
pulse) were analyzed in two ways. First, group $\times$ trial ANOVAs were conducted. In the case of BP and pulse rate, these were group $\times$ trial $\times$ recording period ANOVAs. Greenhouse-Geisser adjusted probabilities were used, because these were repeated measures analyses. Then, for losing trials, group $\times$ trial outcome (out of time vs. hit a mine) ANOVAs were performed on systolic and diastolic BP and pulse measured after the end of play, the mean rating sent after each trial, and the acoustic voice measures. Spearman's rho was used to calculate correlations between trait variables and outcome measures.

\section{RESULTS}

\section{Biochemical Measures}

Mean plasma tryptophan rose in the $\mathrm{T}+$ group from $66.9 \mu \mathrm{mol} / 1$ to $664.4 \mu \mathrm{mol} / \mathrm{l}$, and fell from $70.2 \mu \mathrm{mol} / 1$ to less than $10 \mu \mathrm{mol} / \mathrm{l}$ in the T-group.

\section{Baseline Trait and State Measures (Table 1)}

There were no significant differences between the groups on any of the trait variables or on the mood factors at baseline (Table 1).

\section{Findings for the Entire Sample (Combined Tryptophan Groups)}

Both groups rated their mood more negatively 4.5 hours after the amino acid drink than at baseline. They rated themselves as angrier $\left(\mathrm{F}_{1,25}=24.89, p<.0001\right)$, more discontented $\left(\mathrm{F}_{1,25}=19.45, p<.0002\right)$ and more restless $\left(\mathrm{F}_{1,25}=27.64, p<.0001\right)$. On the Tanks game, there were significant linear trends over the trials for start time $\left(\mathrm{F}_{1,24}=16.57, p<.0005\right)$ and rating time $\left(\mathrm{F}_{1,24}=\right.$ 13.67, $p<.002)$, reflecting faster starting and rating times as the game progressed. Recording period (wait, play, end) had a significant effect on BP and pulse (systolic BP: $\mathrm{F}_{2,48}=19.25, p<.0001$; diastolic BP: $\mathrm{F}_{2,48}=$ 29.46, $p<.0001$; pulse: $\left.\mathrm{F}_{2,48}=45.800, p<.0001\right)$. Systolic and diastolic BP were lowest during the pre-play wait and highest after the end of play. Pulse was highest during the pre-play wait and lowest during play. The mean number of tanks won, lost by hitting a mine, and lost by running out of time were 1.0, 16.7, and 2.3, respectively. Subjects in both groups sent high ratings to their partners on winning trials. On losing trials, they sent more negative ratings if the tank had hit a mine than if they had lost by running out of time $\left(\mathrm{F}_{1,20}=\right.$ $47.51, p<.0001)$. Sending negative ratings after hitting a mine correlated with attributing nonintentional blame to the partner ( $\mathrm{r}=0.57, p<.005)$; whereas, sending negative ratings after running out of time correlated with attributing intentional blame $(\mathrm{r}=0.46, p<.05)$. After the Tanks game, subjects rated themselves as angrier (mean ARS: $\mathrm{F}_{1,25}=5.13, p<.05$ ) and more anxious (MRS Factor 3: $\mathrm{F}_{1,25}=8.53, p<.01$ ). There were no effects of trial outcome on the fundamental frequency or its amplitude or on the energy in the lowest two bands (collectively, 80 to $512 \mathrm{~Hz}$ ). The 3rd and 4th bands (512-1024 and 1024-2048 Hz) showed a pattern of results, significant in the 4th, of higher energy levels after losing by running out of time than after losing by hitting a mine $\left(\mathrm{F}_{1,14}=5.67, p<.05\right)$. Results for the winning trials must be treated cautiously, because of the small numbers involved. However, they suggest higher

Table 1. Means \pm Standard Deviations of Trait Variables for Participants in the Two Groups

\begin{tabular}{llrr}
\hline & & $\begin{array}{c}\text { Enhanced Group } \\
(\boldsymbol{n}=\mathbf{1 4})\end{array}$ & $\begin{array}{c}\text { Depleted Group } \\
(\boldsymbol{n}=\mathbf{1 3})\end{array}$ \\
\hline Hostility & Assault & $6.1 \pm 1.7$ & $6.3 \pm 2.4$ \\
BDHI & Motor aggression & $28.6 \pm 3.4$ & $28.8 \pm 5.0$ \\
& Attitudinal hostility & $6.9 \pm 3.5$ & $8.4 \pm 4.1$ \\
& Guilt & $3.4 \pm 2.0$ & $4.2 \pm 2.0$ \\
Tmpulsivity & Cotal & $42.3 \pm 6.0$ & $44.4 \pm 9.2$ \\
BIS-11 & Motor impulsivity & $13.4 \pm 5.0$ & $14.3 \pm 5.3$ \\
& Nonplanning & $19.8 \pm 6.7$ & $18.4 \pm 6.4$ \\
Behavioral & BIS & $27.5 \pm 4.7$ & $24.2 \pm 9.2$ \\
inhibition and & BAS reward & $15.7 \pm 3.0$ & $16.5 \pm 2.8$ \\
activation & Responsiveness & $16.9 \pm 1.5$ & $17.6 \pm 1.9$ \\
BIS/BAS & BAS Drive & & $10.2 \pm 2.9$ \\
scales & BAS fun-seeking & $10.8 \pm 1.3$ & $12.9 \pm 2.5$ \\
Depression & & $13.5 \pm 1.6$ & $8.8 \pm 5.9$ \\
BDI & & & \\
Anxiety & & $6.6 \pm 5.1$ & $43.4 \pm 8.4$ \\
STAI & & $40.4 \pm 8.0$ & \\
\hline
\end{tabular}


levels of energy in the speech signal after winning than after losing. This was most evident in the higher frequency bands (band 5: $\mathrm{F}_{1,6}=14.04, p<.05$; band 6: $\mathrm{F}_{1,6}=$ 14.24, $p<.05$; band 7: $\left.\mathrm{F}_{1,6}=30.82, p<.005\right)$, although also apparent to some extent in the lowest band $\left(\mathrm{F}_{1,6}=\right.$ $8.66, p<.05)$.

\section{Effects of Tryptophan Manipulation: Pregame Differences Between the Groups}

The T-group showed greater increases in ratings of restlessness $\left(\mathrm{F}_{1,25}=7.72, p<.01\right)$ and incompetence (MRS item 12: $\left.\mathrm{F}_{1,24}=8.35, p<.01\right)$ than the $\mathrm{T}+$ group. See Figure 1 . There were no other significant differences between the groups in reported mood. However, correlations between BDI scores and changes on the MRS item happy-sad differed between the two groups $(n(0,1)=2.25, p<.05)$; more depressed subjects in the $\mathrm{T}+$ group becoming happier $(\mathrm{r}=-.56, p<.05)$ and $\mathrm{a}$ tendency for depressed subjects in the $\mathrm{T}-$ to become sadder $(\mathrm{r}=0.35)$.

\section{Effects of Tryptophan Manipulation: Postgame Differences Between the Groups}

The $\mathrm{T}-$ group performed worse on the game $\left(\mathrm{F}_{1,25}=\right.$ $4.28, p<.05)$. The mean scores $( \pm \mathrm{SD})$ were $5.86 \pm 3.82$ for the $\mathrm{T}+$ group and $3.15 \pm 2.85$ for the $\mathrm{T}-$ group. There were no between-group differences on the mean ratings sent to the partner over the whole game or on winning trials. However, analysis of the ratings sent on losing trials revealed a group $\times$ reason for losing interaction $\left(\mathrm{F}_{1,20}=8.73, p<.01\right)$, reflecting more negative ratings from the $\mathrm{T}-$ group after losing by running out of time. The decrease in rating time over the game was more marked in the depleted group $\left(\mathrm{F}_{1,24}=4.98, p<\right.$ $.05)$, who were particularly slow on early trials. There were also significant group $\times$ trial interactions for systolic $\left(\mathrm{F}_{19,456}=4.59, p<.005\right)$ and diastolic $\mathrm{BP}\left(\mathrm{F}_{19,456}=\right.$ $3.15, p<.05)$. BP tended to rise during the game in the depleted group and to fall in the enhanced group. See Figure 2. The increase in self-rated incompetence following the game was greater in the $\mathrm{T}-$ group $\left(\mathrm{F}_{1,24}=5.16\right.$, $p<.05)$, who also showed a greater move toward the

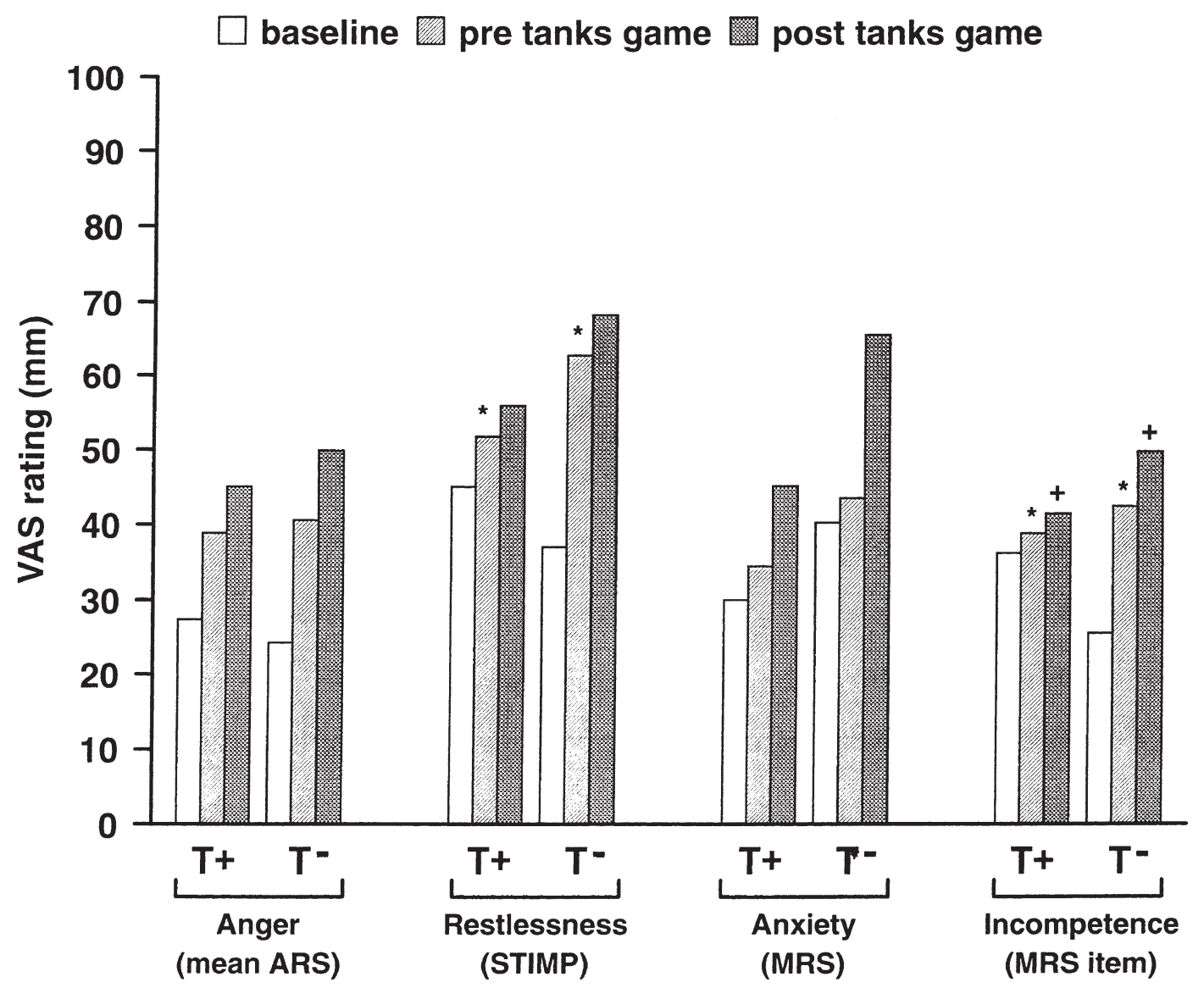

Figure 1. Significant changes in VAS self-ratings of mood states * Significant difference between $\mathrm{T}+$ and $\mathrm{T}-$ groups in baseline-to-pre-Tanks game change. 1 Significant difference between $\mathrm{T}+$ and $\mathrm{T}-$ groups in pre-Tanks game to post-Tanks game change. 


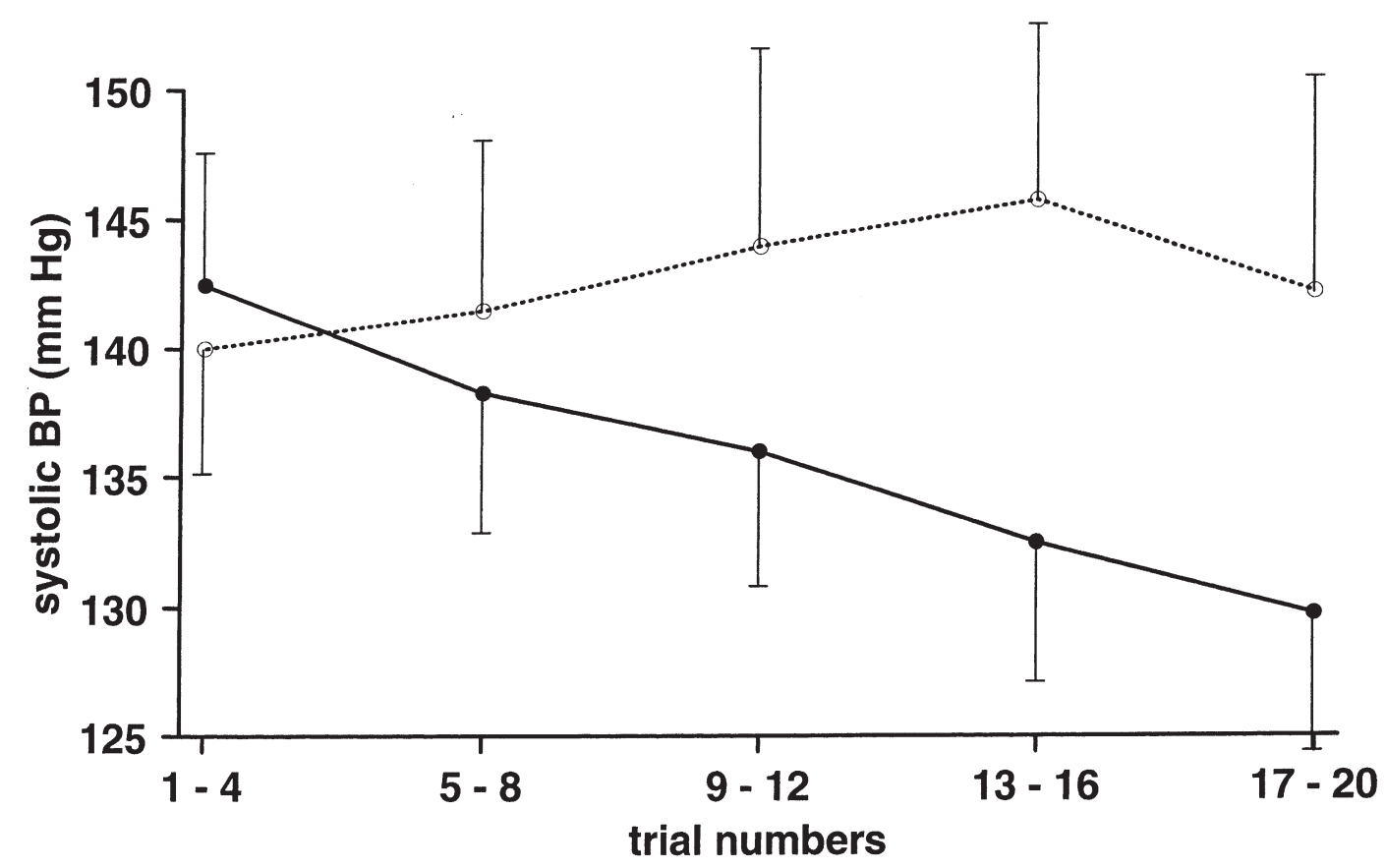

Figure 2. Systolic blood pressure during play over trials of the Tanks game.

"energetic" pole of the MRS item lethargic-energetic $\left(\mathrm{F}_{1,25}=4.73, p<.05\right)$.

Analysis of acoustic voice parameters revealed some differences between the groups. On losing trials, the group reason for losing interaction was significant for the top band $\left(\mathrm{F}_{1,14}=4.66, p<.05\right)$, with similar nonsignificant trends in the 5 th and 6 th bands $\left(\mathrm{F}_{1,14}=4.10, p<\right.$ 007 and $\mathrm{F}_{1,14}=3.73, p<.08$ ) and indicated that the enhanced group showed the same pattern as for lower bands with increased energy after running out of time rather than hitting a mine. The depleted group, on the other hand, showed decreased energy in these high-frequency bands after running out of time. A comparison of winning and losing trials found a group by outcome interaction in the highest band $\left(\mathrm{F}_{1,6}=7.45, p<.05\right)$ suggesting a greater increase in high-frequency energy associated with winning in the depleted group. There were similar nonsignificant trends in the 5th and 6th bands. Overall, the results of the speech signal analysis suggest that the depleted group showed changes in the amount of high-frequency energy associated with different tank outcomes, consistent with the view that they were more excited by winning and more deflated by nearly winning than the enhanced group. The correlations of the BAS Drive and the BDHI subscales assault and guilt with reactions to the Tanks game differed between the groups. BAS Drive was correlated with sending negative ratings in the $\mathrm{T}$ - group $(\mathrm{r}=.68, p<.05)$ but not in the $\mathrm{T}+$ group $(\mathrm{r}=-0.10$, difference between correlations $n(0,1)=2.01$, $p<.05)$. BAS drive also showed different correlations with affective reactions to the game in the two groups, with a tendency for high BAS drive scorers to become angrier and more discontented after playing the game when depleted but less so after playing the game when enhanced (anger $\mathrm{T}+\mathrm{r}=-0.44, \mathrm{~T}-\mathrm{r}=0.40, n(0,1)=2.00$, $p<.05$; discontented $\mathrm{T}-\mathrm{r}=0.62, p<.05, \mathrm{~T}+\mathrm{r}=-0.44$, $n(0,1)=2.67, p<.01)$. The $\mathrm{T}-$ group showed correlations between BDHI assault and increased anger $(r=.83$, $p<.01)$, restlessness $(\mathrm{r}=0.72, p<.01)$ and anxiety $(\mathrm{r}=$ $0.64, p<.05)$. The corresponding correlations for the $\mathrm{T}+$ group were $0.11,-0.03$, and -0.13 , respectively, and the differences between the correlations were significant $[n(0,1)=2.44, p<.05, n(0,1)=2.06, p<0.05$, and $n(0,1)=$ $1.97, p<.05$, respectively). In the $\mathrm{T}-$ group, guilt was correlated with increased anger $(\mathrm{r}=0.67, p<.05)$, and restlessness $(\mathrm{r}=0.73, p<.01)$. [The corresponding correlations for the $\mathrm{T}+$ group were -0.49 and -0.47 ; differences between groups $n(0,1)=2.99, p<.01$, and $n(0,1)=$ 3.20, $p<.01$, respectively.] Thus, depleted participants with high scores on assault and guilt were most likely to become angry after playing the Tanks game, and those with high scores on BAS drive to send negative ratings to their partners.

\section{DISCUSSION}

Although the differences between the enhanced and depleted groups on the primary measures of anger and verbal aggression were not significant in this study, the 
results do shed light on some of the processes and traits that may mediate previously found effects of tryptophan depletion on aggression. It is, however, important to acknowledge that there was no pharmacologically inactive control condition in this study; therefore, comparisons can only be made between tryptophan depletion and enhancement conditions.

The depleted group showed greater increases in selfreported restlessness, a scale that includes the items, "find waiting difficult" and "want to get things done quickly." This result supports the argument of Soubrie (1986) that serotonin is involved in the ability to tolerate delay. It is also consistent with the hypothesis that tryptophan depletion increases the probability of aggressive behavior by increasing impulsivity; the combination of increased impulsivity and high trait hostility results in aggressive behaviour. This interpretation is in accord with the finding of Cleare and Bond (1995) that both low- and high-hostility groups were quicker to set noise volumes for their opponents when depleted than when enhanced, but these volumes were only higher in the high-hostility participants. The results obtained here further suggest that those scoring high on assault may be particularly susceptible to a tryptophan depletioninduced increase in impulsivity, although this was only evident on the behavioral impulsivity subscale. On the other hand, depleted participants were slower in sending ratings early in the game, catching up on later trials. Clearly, these times will also have been influenced by such other factors as vigilance to the cues indicating that a response is required. Further research with highand low-hostility groups and a range of measures to tap different aspects of impulsivity would help to clarify how far impulsivity mediates the effect of depletion on aggression.

Velasco and Bond (1998) found that restlessness was one of the main bodily sensations mentioned when people described situations in which they felt angry. Therefore, it is possible that tryptophan depletion leads to changes that can be labeled as restlessness or anger, depending upon the situation.

The depleted group also reported greater increases in perceived incompetence at 4.5 hours. Similar increases on this scale following depletion have previously been reported in healthy men with a family history of affective disorder by Benkelfat et al. (1994). A similar trend was found in healthy women volunteers by Ellenbogen et al. (1996). This could reflect a lowering of confidence and self-esteem or it could be that participants are noticing genuine cognitive impairment. There is evidence that tryptophan depletion impairs performance on some tasks (e.g., Park et al. 1994), and here the depleted participants performed significantly worse on the Tanks game. However, it is worth noting that the overwhelming experience of all participants was of fail- ure. The model of aggression proposed by Baumeister et al. (1996) suggests a key role for threatened egotism and unstable high self-esteem. Therefore, whether valid or not, a tryptophan depletion-induced feeling that one is less competent than usual may increase the probability of angry and aggressive reactions to subsequent frustration or provocation in some individuals.

The greater increases in restlessness and feelings of incompetence over the day shown by the depleted group were followed by different reactions to the game. One of the most striking was the increase in diastolic and systolic blood pressure shown by the depleted group while playing the Tanks game. This could reflect differences in anger that was not expressed in the selfratings, or it could, perhaps more plausibly, reflect a difference in the extent to which the subjects were involved with the task and an increased concern with winning and losing in the depleted group. Velasco and Bond (1998) showed the importance of personal relevance in autonomic reactivity to emotion-inducing scenarios. Healy (1998) describes the role of the serotonergic system in enabling people to maintain a measure of sanguinity in the face of stressful events. This may best describe what the depleted subjects lacked. Acoustic analysis of the verbal messages sent as feedback showed increased high-frequency energy after winning and decreased high-frequency energy after losing by running out of time in the depleted group, as compared to the enhanced group. Previous research suggests that increases in high-frequency energy reflect arousal and excitement, and decreases reflect sadness (Scherer 1995). It seems then that the depleted subjects may have been more excited when they won and more deflated when they ran out of time.

The feedback ratings participants sent to their partners after playing each tank were almost uniformly positive after winning, intermediate after losing by running out of time, and least favorable after losing by hitting a mine. This makes sense, because it is the partner's role to send directions to avoid the mines. However, the ratings sent by the tryptophan-depleted group were less influenced by the reason for losing. This could reflect less attention to the cues, indicating the reason for losing (i.e., the time elapsed since start of play and the clock face in the top left of the screen). Certainly, decreased attention to situational cues is one potential explanation for increased aggression in some circumstances. Finding it harder to divide attention between steering the tank through the gaps in the walls and reading the directions at the top of the screen is also a possible explanation for the poorer performance of the depleted group. On the other hand, the similar interaction between group and trial outcome found for the high-frequency voice energy, and the similar trend for systolic blood pressure, suggest that perhaps all these 
measures reflect a more negative emotional response in the tryptophan-depleted participants to loss from running out of time. When a tank is lost by running out of time, the goal is in sight, making this potentially more frustrating than losing earlier in play. A previous study found a correlation between BAS drive and sending negative messages after running out of time (Wingrove and Bond 1998). Therefore, the results obtained here might be explained by suggesting that the depletion acts to make the subjects more goal driven, so they experience the frustration of "nearly winning" more keenly, with the consequent effects on ratings, blood pressure, and voice characteristics that were observed. A greater concern with winning and losing, and, thus, a greater tendency to experience frustration, could certainly increase the probability of aggression in some individuals.

There were no differences between the groups in the attribution of blame to self or partner, and there were no differences in the number of critical comments or apologies in the analysis of voice content. This suggests that tryptophan enhancement/depletion does not have a direct effect on the cognitive component of hostility.

Previous research suggests that the effects of tryptophan depletion on mood depend on trait variables (e.g., Benkelfat et al. 1994; Cleare and Bond 1995) and, possibly also on the experimental environment. The current results support this view. The significant difference between the correlations of the Beck Depression Inventory with changes on the mood rating "happy sad" for the enhanced and depleted groups suggest that people with higher depression scores are most susceptible to the effect of depletion increasing, and enhancement decreasing, sadness. However, the greatest effect of trait measures on responses to depletion/enhancement became manifest in participants' reactions to the Tanks game. Those who scored high on assault, guilt, and BAS drive showed the greatest increases in selfreported anger and impulsivity following the Tanks game in the depleted but not the enhanced condition. High BAS drive scores were also associated with sending negative ratings to the partner in the depleted condition only. The results confirm the view that emotional and behavioral reactions to tryptophan manipulation crucially depend upon pre-existing individual differences and situational demands.

The results also raise the possibility that tryptophan depletion does not have direct effects on anger or aggression, but rather leads to other changes, which then, in certain circumstances, can result in anger and aggression in predisposed individuals. These include increased restlessness/impulsivity, increased concern with winning and losing, involving more negative reactions to failure/frustration, increased autonomic reactivity, and decreased perceived self-competence.

\section{REFERENCES}

Baumeister RF, Smart L, Boden JM (1996): Relation of threatened egotism to violence and aggression: The dark side of high self-esteem. Psychol Rev 103:5-33

Baumgarten HG, Grozdanovic Z (1995): Psychopharmacology of central serotonergic systems. Pharmacopsychiatry 28:73-79

Beck AT, Ward CH, Mendelson M, Mock J, Erbaugh J (1961): An inventory for measuring depression. Arch Gen Psychiat 4:561-571

Benkelfat C, Ellenbogen MA, Dean P, Palmour RM, Young SN (1994): Mood-lowering effect of tryptophan depletion: Enhanced susceptibility in young men at genetic risk for major affective disorders. Arch Gen Psychiat 51:687-97

Bond AJ, Lader MH (1974): The use of analogue scales in rating subjective feelings. Br J Med Psychol 47:211-218

Bond AJ, Lader MH (1986): A method to elicit aggressive feelings and behavior via provocation. Biolog Psychol 22:69-79

Brown GL, Goodwin FK, Ballenger PF, Goyer PF, Major LF (1979): Aggression in humans correlates with cerebrospinal fluid amine metabolites. Psychiat Res 1:131139

Buss AH, Durkee A (1957): An inventory for assessing different kinds of hostility. J Consult Psychol 21:343-349

Carver CS, White TL (1994): Behavioral inhibition, behavioral activation, and affective responses to impending reward and punishment: The BIS/BAS scales. J Pers Soc Psychol 67:319-333

Cleare AJ, Bond AJ (1995): The effect of tryptophan depletion and enhancement on subjective and behavioral aggression in normal male subjects. Psychopharmacology 118:72-81

Coccaro EF, Berman ME, Kavoussi RJ, Hauger RL (1996): Relationship of prolactin response to d-fenfluramine to behavioral and questionnaire assessments of aggression in personality-disordered men. Biol Psychiat 40:157-164

Danjou P, Harmon M, Lacamblex L, Kecskemeti S, Puech AJ (1990): Psychomotor, subjective, and neuroendocrine effects of acute tryptophan depletion in the healthy volunteer. Psychiat Psychobiol 5:31-38

Ellenbogen MA, Young SN, Dean P, Palmour RM, Benkelfat C (1996): Mood response to acute tryptophan depletion in healthy volunteers: Sex differences and temporal stability. Neuropsychopharmacology 15:465-474

Eriksson T, Lidberg L (1997): Increased plasma concentrations of the 5-HT precursor amino acid tryptophan and other large neutral amino acids in violent criminals. Psychol Med 27:477-481

Finn PR, Young SN, Pihl RO, Ervin FR (1998): The effects of acute plasma tryptophan manipulation on hostile mood: The influence of trait hostility. Aggress Behav 24:173-185

Healy D (1998): Reboxetine, fluoxetine, and social functioning as an outcome measure in antidepressant trials: Implications. Primary Care Psychiat 4:81-89

Higley JD, Mehlman PT, Poland RE, Taub DM, Vickers J, 
Suomi SJ, Linnoila M (1996): CSF testosterone and 5-HIAA correlate with different types of aggressive behaviors. Biol Psychiat 40:1067-1082

Menkes DB, Coates DC, Fawcett JP (1994): Acute tryptophan depletion aggravates premenstrual syndrome. J Affective Disord 32:37-44

Moeller FG, Dougherty DM, Swann AC, Spence D, Davis CM, Cherek DR (1996): Tryptophan depletion and aggressive responding in healthy males. Psychopharmacology 126:97-103

Park SB, Coull JT, McShane RH, Young AH, Sahakian BJ, Robbins TW, Cowen PJ (1994): Tryptophan depletion in normal volunteers produces selective impairments in learning and memory. Neuropharmacology 33:575-588

Patton JH, Stanford MS, Barratt ES (1995): Factor structure of the Barratt Impulsiveness Scale. J Clin Psychol 51:768774

Pihl RO, Young SN, Harden P, Plotnick S, Chamberlain B, Ervin FR (1995): Acute effect of altered tryptophan levels and alcohol on aggression in normal human males. Psychopharmacology 119:353-360

Salomon RM, Mazure CM, Delgado PL, Mendia P, Charney DS (1994): Serotonin function in aggression: The effect of acute plasma tryptophan depletion in aggressive patients. Biol Psychiat 35:570-572

Scherer KR (1995): Expression of emotion in voice and music. J Voice 9:235-248

Smith SE, Pihl RO, Young SN, Ervin FR (1986): Elevation and reduction of plasma tryptophan and their effects on aggression and perceptual sensitivity in normal males. Aggress Behav 12:393-407

Spielberger CD, Gorusch RL, Lushene RE (1970): Manual for the State-Trait Inventory (Self-Evaluation Questionnaire). Palo Alto, California, Consulting Psychologists Press

Soubrie P (1986): Reconciling the role of central serotonin neurons in human and animal behavior. Behav Brain Sci 9:319-364

Velasco C, Bond AJ (1998): Personal relevance is an important dimension for visceral reactivity in emotional imagery. Cognition Emot 12:231-242

Verhoeven WMA, Tuinier S (1997): Biological and psychopharmacological aspects of impulse-control disorders. Acta Neuropsychiat 9:89-93

Weltzin TE, Fernstrom MH, Fernstrom JD, Neuberger SK, Kaye WH (1995): Acute tryptophan depletion and increased food intake and irritability in bulimia nervosa. Am J Psychiat 152:1668-1671

Wingrove J, Bond AJ (1997): Impulsivity: A state as well as trait variable. Does mood awareness explain low correlations between trait and behavioral measures of impulsivity? Person Individ Diff 22:333-339

Wingrove J, Bond AJ (1998): Angry reactions to failure on a cooperative computer game: The effect of trait hostility, behavioral inhibition, and behavioral activation. Aggress Behav 24:27-36

Young SN, Smith SE, Pihl RO, Ervin FR (1985): Tryptophan depletion causes a rapid lowering of mood in normal males. Psychopharmacology 87:173-177 